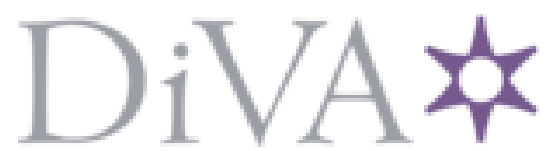

http://www.diva-portal.org

\title{
Preprint
}

This is the submitted version of a paper published in Complementary Therapies in Clinical Practice.

Citation for the original published paper (version of record):

Bergdahl, L., Broman, J-E., Berman, A H., Haglund, K., von Knorring, L. et al. (2017)

Sleep patterns in a randomized controlled trial of auricular acupuncture and cognitive behavioral therapy for insomnia.

Complementary Therapies in Clinical Practice, 28: 220-226

https://doi.org/10.1016/j.ctcp.2017.06.006

Access to the published version may require subscription.

N.B. When citing this work, cite the original published paper.

Permanent link to this version:

http://urn.kb.se/resolve?urn=urn:nbn:se:uu:diva-320044 


\section{Sleep patterns in a randomized controlled trial of Auricular Acupuncture and Cognitive Behavioral Therapy for insomnia}

Lena Bergdahl $^{1}$, RN, BSc, PhD candidate, Jan-Erik Broman ${ }^{1,2}$, RN, BSc, PhD, Anne H

Berman $^{3}$, Lic. Psychologist, PhD, Kristina Haglund ${ }^{1}$, RN, MSc, PhD, Lars von Knorring ${ }^{1}$, $\mathrm{MD}, \mathrm{PhD}$, Agneta Markström², MD, PhD

(Submitted 170201 to Complementary Therapies in Clinical Practice, Ref: CTCP_2017_41)

1) Department of Neuroscience, Psychiatry

Uppsala University

SE-751 85 Uppsala, Sweden

2) Department of Medical Sciences, Lung, Allergy and Sleep

Research

Uppsala University

SE-751 85 Uppsala, Sweden

3) Department of Clinical Neuroscience, Center for Psychiatry

Research

Karolinska Institutet

Norra Stationsgatan 69

SE-113 64 Stockholm, Sweden

Contact information

Lena Bergdahl, $\mathrm{PhD}$ candidate (author for correspondence):

lena.bergdahl@neuro.uu.se

Jan-Erik Broman, PhD, Associate Professor:

jan-erik.broman@neuro.uu.se

Anne H Berman, PhD, Associate Professor:

anne.h.berman@ki.se

Kristina Haglund, PhD, Associate Professor:

kristina.haglund@neuro.uu.se

Lars von Knorring, Professor emeritus: 
lars.von_knorring@neuro.uu.se

Agneta Markström, PhD, Associate Professor:

agneta.markstrom@akademiska.se

\section{Corresponding Address}

Lena Bergdahl, RN, BSc, PhD student (author for correspondence):

Department of Neuroscience, Psychiatry,

Uppsala University

SE-751 85 Uppsala,

Sweden

E-mail: lena.bergdahl@neuro.uu.se 


\author{
Abbrevations \\ Auricular acupuncture (AA) \\ Cognitive behavioural therapy for insomnia (CBT-i) \\ Diagnostic and statistical manual of mental disorders, fifth edition (DSM-5) \\ Health-related quality of life (HRQoL) \\ Insomnia Severity Index (ISI) \\ Mental component summary (MCS) \\ National Acupuncture Detoxification Association (NADA) \\ Physical component summary (PCS) Polysomnography (PSG) \\ Randomized controlled study (RCT) \\ Short Form 12 (SF-12) \\ Standard deviation (SD) \\ Standard error (SE)
}




\begin{abstract}
The aim of the study was to objectively examine how sleep patterns were affected in a shortand long-term perspective after auricular acupuncture (AA) and cognitive behavioral therapy for insomnia (CBT-i). Sixty participants with insomnia disorders (men/women 9/51; mean age of 60.5 years, (SD 9.4)), were randomized to group treatment with AA or CBT-i.

Actigraphy recordings were made at baseline, post-treatment and 6-month follow-up. The CBT-i group reduced their time in bed, their actual sleeping time, their sleep latency and their actual time awake. The AA group slept longer, increased their time in bed and decreased their sleep latency post-treatment. The between-groups results differed in wake-up time, rising, time in bed, actual sleep time and actual wake time. The differences were not maintained six months later. In accordance with previous findings the results support the notion that the objective sleep time does not necessarily affect the subjective perception of insomnia.
\end{abstract}

Keywords: auricular acupuncture, cognitive-behavioral therapy, insomnia disorder, actigraphy, treatment, non-pharmacological 



\section{Introduction}

Insomnia is a common problem in the general population (e.g 1) and is known to be associated with psychiatric and somatic comorbidities $(2,3,4,5)$. The diagnosis is characterised by difficulties initiating and/or maintaining sleep as well as residual daytime symptoms three times a week or more often during a period of 3 months or more (6). The perception of good or bad sleep is also related to age and gender $(7,8,9)$. Insomnia may influence different aspects of life, and in a review by Kyle et al. (10) it was concluded that insomnia has a negative influence on different aspects of health-related quality of life (HRQoL), adequate treatment of insomnia can, however, lead to significant improvements.

Insomnia can be measured in various ways, objective as well as subjective (e.g. 11). When it comes to objective measurements, polysomnography (PSG) is considered to be the golden standard of sleep assessment (12). PSG can be performed in the laboratory or at home. Despite the fact that PSG can be used to determine the different sleep stages and the total sleep time, it is not primarily used to diagnose insomnia, but rather other sleep disorders such as narcolepsy, sleep disordered breathing disorders and parasomnia (12). Actigraphy is another objective method to measure physical activity, and it is also, indirectly, used to study sleep-wake patterns by assessing movement (13). The actigraph is a portable device, measuring movements by being attached to the non-dominant wrist. One of the advantages of actigraphy is that, in comparison to PSG, it is possible to record many days and nights without a significant intrusion in a person's everyday life. It also allows the patient to sleep in the natural sleep environment. According to a review by Ancoli-Israel et al. (13) the majority of the literature shows that the reliability and validity of actigraphy is moderate to high in differentiating sleep from wake in a healthy population. Vallières et al. (14) performed a study where actigraphy was compared to PSG and sleep diary. The results confirmed actigraphy as a reliable method for assessing insomnia disorder. In a population with fragmented sleep, the reliability of actigraphy was questioned by Paquet et al. (15), who performed a study using actigraphy and PSG during one nocturnal sleep episode and two daytime recovery sleep episodes. The results, in accordance with previous research by Sivertsen et al. (16), demonstrated that actigraphy was less reliable than PSG for detecting wakefulness (15). Rowe et al. (17) however found that a minimum measurement period of seven days was required to obtain reliable information regarding sleep parameters. To establish insomnia diagnosis, subjective methods such as a clinical interview according to the diagnostic and statistical manual of mental disorders, fifth edition (DSM-5) criteria (6), combined with self-report 
questionnaires, is standard procedure. A sleep diary or sleep log can also be used to monitor the sleep-wake pattern. Insomnia symptoms are subjective (18) and the experience of the symptoms, measured with subjective measurements, does not necessarily correlate with the objective measurements since persons with insomnia tend to underestimate their total sleep time as well as overestimating time spent awake in bed (19). While objective measurements can show an improved actual sleep time after an intervention, subjective measurements may not necessarily reflect the improvement $(19,20,21,22)$.

There are various ways to treat insomnia. Over the last two decades interest has increased in developing non-pharmacological insomnia treatments, an effort that enables reduction of hypnotic drug dosages as well as side effects (23). The most effective non-pharmacological treatment is cognitive behavioral therapy for insomnia (CBT-i) (24). The components of CBT-i include cognitive techniques addressing common insomnia-related features such as rumination and dysfunctional beliefs and attitudes towards sleep, and behavioral techniques addressing practical aspects such as sleep restriction (e.g 25). Another non-pharmacological treatment that has been tested to treat insomnia is acupuncture (26). Acupuncture is a complementary treatment method, which to some extent is used in the health care system, for example within maternity care and pain management (27). Auricular acupuncture (AA) is a branch of traditional acupuncture and has also been used to treat insomnia $(22,28,29,30)$. Given that objective measurements do not always correlate with subjective measurements and that there are very few studies of AA for insomnia where objective measurements of the sleep patterns are used $(22,31,32)$, we found it important to report the effects of CBT-i and AA with an objective sleep measurement. In a recent study we compared the treatment effects of AA and CBT-i regarding the subjective symptoms of insomnia severity (33), using the Insomnia Severity Index (ISI) (34) as the primary outcome. The results showed that CBT-i significantly improved subjective insomnia symptoms compared to AA.

In the present report our aim was to use an objective measurement method, actigraphy, to examine how sleep patterns were affected in a short- and long-term perspective after AA- and CBT-i, as well as to compare sleep parameters related to these patterns between the two treatment forms.

\section{Materials and Methods}


This was a prospective randomized controlled study (RCT) using actigraphy to examine sleep patterns and evaluate treatment effects of AA and CBT-i in a short- and long-term perspective.

\subsection{Participants}

The participants and the inclusion- and exclusion criteria and the procedure are described in detail in Bergdahl et al. (33). To briefly summarize, participants in the study sample, 51 women and 9 men $(\mathrm{N}=60)$, with a mean age of 60.5 (SD 9.4) years, had experienced insomnia symptoms for more than six months. All had used non-bensodiazepine hypnotics for a mean of 7.3 years (SD 5.6), but even with the pharmacological treatment the insomnia symptoms persisted and the participants wanted to end their medication. All participants were instructed to end their hypnotic drug treatment three to five days before the treatment start.

\subsection{Procedure}

Participants were recruited by advertisement in the local newspaper and from an outpatient sleep clinic. All subjects were informed that participation was voluntary and that they could withdraw from the study at any time without any negative consequences. In total 204 persons were assessed for eligibility. The 67 participants who fulfilled the inclusion criteria met with an experienced medical sleep specialist (senior author AM) who assessed all subjects before inclusion. After signing the informed consent form, the participants were given an actigraph to wear on their non-dominant wrist. Instructions on how to use it were given verbally and in writing; participants were instructed to wear the actigraph during seven days and nights in order to register 24-hour activity patterns, where the focus was the sleep periods. To indicate when they went to bed at night and when they rose in the morning they were instructed to press the actigraphy event marker. During the inclusion session the participants also completed the SF-12. Follow-up actigraphy recordings and SF-12 was performed directly post-treatment and six months after the end of the treatment.

Randomization to group treatment with AA $(n=32)$ or CBT- $(n=35)$ was carried out after the inclusion session. The randomization procedure is described in detail in Bergdahl et al. (33). For participant flow during the study, see Figure 1. 


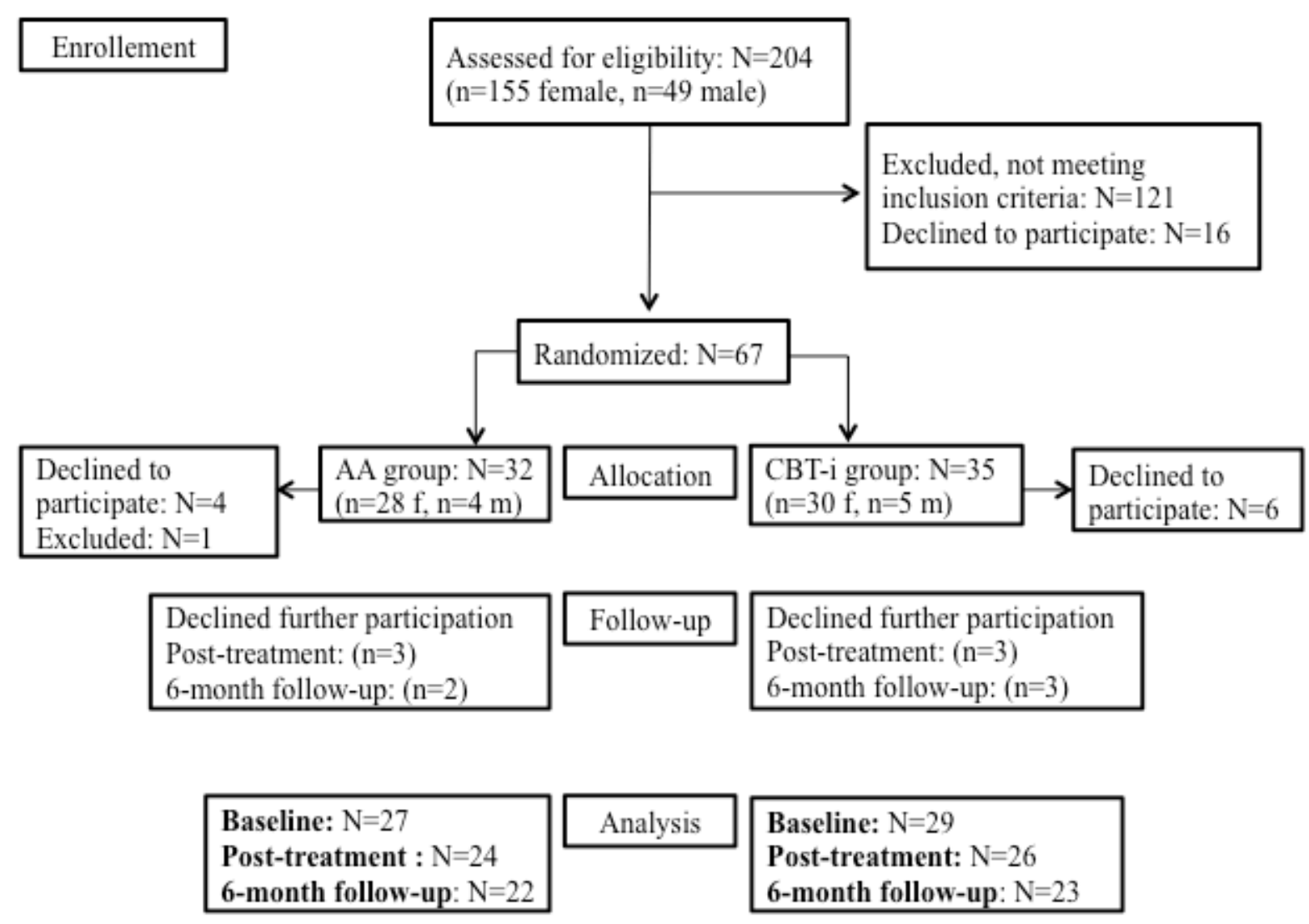

Figure 1. CONSORT flow diagram of participants during the study.

\subsection{The treatments}

Extended treatment descriptions are given in Bergdahl et al. (33), and only summarized briefly below. Both treatments were performed in hospital facilities for outpatients.

\subsubsection{AA}

The AA group $(\mathrm{n}=27)$ was scheduled for treatment sessions twice a week during four weeks. The standardised National Acupuncture Detoxification Association (NADA) protocol, according to the Nogier's European ear map, was used. The acupuncture points used in the NADA protocol are Shen Men, Sympathetic, Kidney, Liver and Lung. In a previous study it was shown that this point selection might have contributed to an improved sleep (35). It has not however, except for the study by Bergdahl et al. (33), previously been tested as a standalone treatment for insomnia disorder. Two NADA-trained members of the psychiatric medical staff, who had long experience of using the method, performed the treatment. During 
every treatment session, which lasted for 45 minutes, the participants received five acupuncture needles in each outer ear, inserted at a depth of three millimetres. Once inserted there was no stimulation of the needles, and after the insertion the acupuncturist left the room. The participants were seated in chairs during the entire time, and when the session was over the acupuncturist removed the needles.

\subsubsection{Equipment}

Sterile stainless Zhongyan Taihe acupuncture needles $(0.18 \times 13 \mathrm{~mm})$ were used. The needles were disposed of after every treatment. Disinfectant solution on the participants' outer ears and the acupuncturists' hands was used before needle insertion.

\subsubsection{CBT-i}

Twenty-nine participants initiated the CBT-i treatment and received a manual-based group treatment (36) once a week during six weeks. The sessions lasted for 90 minutes and included guidance in sleep restriction, information about sleep physiology, how to cope with sleeping problems, maintaining factors and stimulus control and relaxing techniques. Three licensed clinical psychologists delivered the treatment; all had prior CBT training and were experienced in delivering CBT-i treatment.

\subsection{Measurements}

\subsubsection{Actigraphy}

The MotionWatch $8 \circledR$ actigraph, (CamNtech Ltd, Cambridge, UK) was used to assess the participants' 24-hours activity pattern and to distinguish sleep from time awake.

The MotionWatch 8 is a light-weighted, wrist-worn tri-axial accelerometer designed to monitor long-term or short-term activity. The sensitivity for movement lies within $0.01 \mathrm{~g}$ to 8 $\mathrm{g}$ and 3 to $11 \mathrm{~Hz}$, and the recorded movements are measured in epochs (i.e time intervals). In the present study the chosen time interval was one-minute epochs. An event button was used by the participants to indicate what time they went to bed and the time of rising in the morning.

The MotionWare 1.1.20 Software was used to download and store data as well as activating the scoring algorithm providing the estimates of various sleep parameters. The sleep parameters derived using the software contained: Bedtime, Fell asleep, Woke up and Rising, the Total time in bed (i.e. the total elapsed time between "Bedtime" and "Rising"), Sleep efficiency (i.e., actual sleep time expressed as a percentage of time in bed), Sleep latency (i.e. 
the time between Bedtime and Fell asleep), Actual sleep time (the total time spent in sleep according to the epoch-by-epoch wake/sleep categorisation) and Actual wake time (i.e. the total time spent in wake according to the epoch-by-epoch wake/sleep categorisation). All parameters were estimated in minutes, except for sleep efficiency, which was estimated in percentages. An experienced sleep technician performed all analyses.

\subsubsection{Short Form-12 (SF-12)}

HRQoL was also assessed with SF-12. The SF-12 is a 12-item health questionnaire, which originates from the more extensive form SF-36. It covers both physical (physical component summary [PCS]) and mental (mental component summary [MCS]) components of health (37). The questions range from 0 to 100 where the lowest number indicates the lowest level of health and vice versa.

\subsection{Statistical analysis}

Treatment effects over time were examined with a series of linear mixed models using the Restricted Maximum Likelihood method, where unstructured variance components were estimated with the actigraph recordings and the SF-12 as outcome variables. More details are available in Bergdahl et al. (33).

\subsection{Ethics}

The project was approved by the Regional Ethical Vetting Board in Uppsala (ref. number 2012/353) and the trial was registered in the ClinicalTrials.gov database (ID: NCT01765959).

\section{Results}

The actigraph results, presented in minutes and in percentages as well as effect sizes and pvalues, are presented in Table 1 and Table 2. The SF-12 results are presented in Table 3.

\subsection{Actigraph recording - within-groups results}

Significant interactions occurred within the groups. Compared to baseline, the CBT-i group went to bed 29.7 (7.2) minutes later post-treatment $(\mathrm{p} \leq 0.001)$ and they woke up and got up $43.3(9.8)(\mathrm{p} \leq 0.001)$ and $45.3(10.0)(\mathrm{p} \leq 0.001)$ minutes earlier than at baseline. They spent less time in bed (74.1 (18.9), $\mathrm{p} \leq 0.001)$ and managed to increase their sleep efficiency by 4.6 (1.4) \% ( $\leq 0.01)$. Sleep latency decreased by $16.4(3.4)$ minutes $(\mathrm{p} \leq 0.05)$ post-treatment, and by $12.8(4.0)$ minutes $(\mathrm{p} \leq 0.01)$ at the 6-month follow-up. There was also a significant 
decrease of the actual sleep time (38.7 (8.6), $\mathrm{p} \leq 0.001)$ as well as the actual wake time (29.9 (4.7), $\mathrm{p} \leq 0.001)$ after the treatment.

The AA group woke up 24.1 (11.5) minutes $(\mathrm{p} \leq 0.05)$ later and increased their time in bed with $17.2(8.1)$ minutes $(\mathrm{p} \leq 0.05)$ after the treatment. They decreased their sleep latency by 7.2 (3.3) minutes $(p \leq 0.05)$ and increased their actual sleep time with $21.4(7.0)$ minutes $(p \leq 0.01)$ after the treatment.

\section{Table 1. Post-treatment Cohen's $d$ 6-mon follow-up Cohen's $d$ Within groups vs Baseline vs Baseline}

Estimate (SE)

Estimate (SE)

\section{Bedtime, min}

AA

CBT-i

Fell asleep, min

$\begin{array}{lllcl}\text { AA } & -1.8(11.0) & 0.05 & -1.1(12.6) & 0.02 \\ \text { CBT-i } & 14.0(7.4) & 0.55 & 5.4(9.2) & 0.15\end{array}$

Woke up, min

AA

24.1 (11.5)*

0.63

$-43.3(9.8) * * *$

1.43

$5.1(12.5)$

0.10

CBT-i

$29.7(7.2)^{* * *}$

1.21

$18.0(9.1)$

0.50

Rising, min

$\begin{array}{lllll}\text { AA } & 21.8(11.4) & 0.57 & -7.3(13.9) & 0.13 \\ \text { CBT-i } & \mathbf{- 4 5 . 3 ( 1 0 . 0 ) * * *} & 1.46 & -6.8(12.0) & 0.14\end{array}$

Time in bed, min

AA

$$
17.2(8.1) *
$$

0.64

$$
-74.1(18.9) * * *
$$

2.06

-11.7 (10.3)

0.30

CBT-i

$$
\%
$$

AA

$$
1.5 \text { (1.4) }
$$

0.33

$4.6(1.4)^{* * *}$

1.07

$-23.6(13.4)$

0.44

CBT-i

$$
4.6(1.4)
$$

Sleep latency, min 

AA
$-7.2(3.3) *$
0.75
$-5.6(4.0)$
0.36
CBT-i
$-16.4(3.4) * * *$
1.58
$-12.8(4.0)^{* * *}$
0.79

Actual sleep time, min

AA

$21.4(7.0)^{* * *}$

0.93

$1.0(91)$

0.03

CBT-i

$-38.7(8.6) * * *$

1.37

$-8.2(11.4)$

0.19

Actual wake time, min
AA
$5.9(5.8)$
0.30
$-4.8(7.2)$
0.17
CBT-i
$-29.9(4.7) * * *$
1.94
$-3.1(6.0)$
0.13

Table 1: Interactions within the groups and Cohen's delta (Cohen's $d$ ); between baseline to post-treatment and between baseline to 6-month follow-up, presented in estimates and standard error (SE).

$* \mathrm{p} \leq 0.05, * * \mathrm{p} \leq 0.01, * * * \mathrm{p} \leq 0.001$

\subsection{Actigraph recording - between-groups results}

Significant interactions occurred between the groups at the baseline to post-treatment followup, but not between baseline and the 6-month follow-up. The groups differed in time of waking up, getting up, time spent in bed, as well as their actual sleep time and actual wake time.

Compared to the baseline the CBT-i group woke up and rose earlier whilst the AA group woke up and rose later $(66.6(15.0), \mathrm{p} \leq 0.001 ; 66.1(15.1), \mathrm{p} \leq 0.001)$ immediately posttreatment. Time spent in bed decreased in the CBT-i group and increased in the AA group (91.2 (0.13.6), $\mathrm{p} \leq 0.001)$. The CBT-i group decreased their actual sleep time and the actual wake time, whereas the AA group increased in these parameters (60.2 (11.2), $\mathrm{p} \leq 0.001 ; 35.9$ (7.4), $\mathrm{p} \leq 0.001)$. 


\begin{tabular}{|c|c|c|c|}
\hline \multirow{2}{*}{$\begin{array}{l}\text { Table } 2 . \\
\text { Between } \\
\text { groups }\end{array}$} & $\begin{array}{l}\text { Post treatment } \\
\text { vs Baseline }\end{array}$ & Cohen's $d$ & $\begin{array}{l}\text { 6-mon follow-up } \\
\text { vs Baseline }\end{array}$ \\
\hline & Estimate (SE) & & Estimate (SE) \\
\hline
\end{tabular}

Bedtime, min

AA

CBT-i

$-24.7(13.1) \quad 0.40$

$-12.9(16.0)$

0.14

Fell asleep, min

AA

CBT-i

$-16.3(13.1) \quad 0.26$

$-6.4(16.1)$

0.07

Woke up, min

AA

CBT-i

$66.6(15.0) * * *$

0.96

$-0.8(18.4)$

0.01

\section{Rising, min}

AA

CBT-i

$66.1(15.1)^{* * *} \quad 0.95$

$-1.4(18.5)$

0.01

Time in bed, min

AA

CBT-i

$$
91.2(13.6)^{* * *}
$$

1.43

$10.9(17.0)$

0.11

Sleep efficiency, \%

AA
CBT-i
$-3.1(2.0)$
0.35
$-0.2(2.2)$
0.02

Sleep latency, min

AA

CBT-i

$9.2(4.8)$

0.46

$7.1(5.6)$

0.22

Actual sleep time, min

AA

CBT-i
$60.2(11.2) * * *$
1.16
$9.0(14.5)$
0.12

Actual wake time, min

AA

CBT-i

$35.9(7.4) * * * \quad 1.01$

$1.7(9.4)$

0.03 
Table 2. Interactions between the groups and Cohen's delta (Cohen's $d$ ); between baseline to post-treatment and between baseline to 6-month follow-up, presented in estimates and standard error (SE). * $\mathrm{p} \leq 0.05, * * \mathrm{p} \leq 0.01, * * * \mathrm{p} \leq 0.001$.

\section{$3.3 S F-12$}

Measurements were made between and within the groups regarding the MCS and PCS at baseline, one week after the treatment and at 6-month follow-up. No significant interactions between the groups were found. Only the CBT-i group showed significant within-group changes; in MCS and PCS there were significant changes post-treatment compared to baseline $(3.4(1.7)(\mathrm{p}<0.05) ; 3.3(1.6)(\mathrm{p}<0.05))$, and in PCS there was also a significant interaction at the 6-month follow-up compared to the baseline $(3.7(1.8)(\mathrm{p}<0.05))$. The within-groups results are presented in Table 3.

$\begin{array}{llllll}\begin{array}{l}\text { Table 3 } \\ \text { Within } \\ \text { groups }\end{array} & \text { Baseline } & \text { Post-treatment } & \text { 6-mon follow-up } & \begin{array}{l}\text { Post-treatment } \\ \text { vs Baseline }\end{array} & \begin{array}{l}\text { 6-mon follow-up } \\ \text { vs Baseline }\end{array} \\ & \begin{array}{l}\text { Estimate } \\ (\mathrm{SE})\end{array} & \text { Estimate (SE) } & \text { Estimate (SE) } & \text { Estimate (SE) } & \text { Estimate (SE) } \\ & & & & \end{array}$

\section{SF-12 MCS}

$\begin{array}{llllll}\text { AA } & 48.6 & 51.2(49.4) & 50.0(49.6) & 2.6(1.4) & 1.4(1.8) \\ & (49.3) & & & & \\ \text { CBT-i } & 47.5 & 50.9(49.1) & 46.1(49.3) & \mathbf{3 . 4}(\mathbf{1 . 7}) * & -1.4(2.3) \\ & (49.6) & & & \end{array}$

\section{SF-12 PCS}

$\begin{array}{llllll}\text { AA } & 48.3 & 48.5(43.3) & 48.2(43.4) & 0.2(1.4) & -0.07(1.5) \\ & (43.4) & & & & \\ \text { CBT-i } & 46.2 & 49.5(43.5) & 49.9(43.0) & \mathbf{3 . 3}(\mathbf{1 . 6})^{*} & \mathbf{3 . 7}(\mathbf{1 . 8}) * \\ & (43.4) & & \end{array}$

Table 3: Within-groups results for Short Form 12 (SF-12), measuring the physical component summary (PCS) and the mental component summary (MCS) from baseline to post-treatment and from baseline to 6-month follow-up. * $\mathrm{p}<0.05$ 


\section{Discussion}

In the previous study (33), where subjective symptoms of insomnia were measured after AA and CBT-i, it was concluded that AA was not considered as a sufficient stand-alone treatment for insomnia. The aim of this report was to use actigraphy to objectively study and compare how sleep patterns were affected over time after AA- and CBT-i.

The results showed that the actual sleep time and time in bed increased in the AA group and decreased in the CBT-i group after the treatments when compared to baseline. The CBT-i group also managed to significantly reduce their actual wake time in bed. There were significant improvements of the sleep latency within both groups after the treatment, a result that was maintained in the CBT-i group at the 6-month follow-up. The sleep efficiency in the CBT-i group improved as well after the treatment, but was not maintained six months later. According to the between-group actigraph recordings, there were significant changes in wakeup time, time of rising, time spent in bed, actual sleep time as well as actual time awake. The sleep latency and sleep efficiency did not differ between the groups at any follow-up point. At the 6-month follow-up there were no significant changes between the groups in any of the parameters and the sleep patterns had reverted to their original parameters.

From these objective results one could draw the conclusion that the sleep patterns at baseline and 6-month follow-up are practically identical and no changes of the sleep pattern had occurred. However, in our previous report, where we reported subjective insomnia symptoms measured with ISI (33), the CBT-i group showed significant improvements after the treatment as well as at the 6-month follow-up in comparison to the AA group. The CBT-i group went from clinical to sub-clinical insomnia while the AA group remained within the range of clinical insomnia measured with ISI. The results taken together show that the insomnia severity decreased for the CBT-i group, even though they slept less according to the actigraph recordings. One explanation for this may be that the shortened sleep latency and the reduced time awake may have contributed to more restful sleep, a result supported by a recent study by Kölling et al. (38), who found that falling asleep quickly had a stronger correlation to the sleep efficiency than the time spent in bed.

The AA group, who according to the recordings slept longer, did not, despite the longer sleep time, experience alleviation in insomnia severity symptoms to the same extent as the CBTgroup. As previously mentioned, there have been very few insomnia-related studies in which AA has been objectively evaluated with actigraphy $(22,31,32)$. The increased actual sleep 
time in the present study is a new finding and a contribution to the field. In the studies by King et al. (22), Yeung et al. (31) or Prisco (32) there were no significant improvements in the total sleep time; however, our finding that sleep latency improved was also found by Yeung et al. (31).

With regard to CBT-i results, our findings are in line with previous research by Friedman et al. (39), Sivertsen et al. (20) and Espie et al. (40). These studies show that the total sleep time, measured by PSG and actigraphy respectively, decreased from baseline to post treatment, but reverted to its pre-study length at the 6-month follow-up. The combined results of the present and the previous (33) reports indicate that a longer sleep time does not necessarily mean better sleep and vice versa. A similar observation was also made in the recent study of Åkerstedt et al. (9), where older women were subjectively more satisfied with shorter and poorer objective sleep than the younger women were.

Insomnia severity symptoms and related daytime symptoms are subjective (41) and may be the reason why patients seek help. From a clinical perspective the results of this study contribute important knowledge, especially since some patients may believe that a satisfying sleep requires a longer sleep time.

Regarding HRQoL there were positive changes in MCS and PCS within the CBT-i group after the treatment, a result that is in accordance with a previous study of Espie et al. (42). There were no significant interactions between the treatment groups.

\subsection{Limitations}

These results are limited to women in the age group represented in this study; thus we do not know if the result is generalizable to other age groups or to men. The number of men is low and it would have been interesting to study if their sleep patterns changed in the same ways as for the women. Due to the limited number of men however, it was not possible to do in this study.

\section{Conclusion}

The results from these objective actigraph recordings showed that the AA group slept more and the CBT-i group slept less after the treatments and that sleep patterns in both groups reverted to pre-treatment levels after six months. Taken together with our previous findings the results show that despite increased sleep time the insomnia symptoms did not decrease within the AA group. The CBT-i group, on the contrary, reduced their sleep time and also 
reduced their insomnia symptoms. Thus, AA, as given in this study, does not improve insomnia symptoms to the same extent as CBT-i and cannot be considered as a sufficient stand-alone treatment. Sleep time does not necessarily affect the perception of insomnia symptoms, and prolonged sleep time does not automatically yield better sleep.

\section{Funding}

This work was supported by Ekhagastiftelsen (grant number: 2011 59); the Medical Training and Research Agreement (ALF); Research and Development (FoU); and Anna-Britta Gustafssons Foundation. No competing financial interests exist.

\section{Contributors}

All authors have made contributions in planning this study. Collection and processing of data was performed by LB and AM. KH managed the 6-month follow-ups.

LB has been the main author. J-EB, AM, AHB, LvK and KH have been co-authors who have contributed with valuable advices and comments on the manuscript. All authors have approved the final version of the manuscript.

\section{Conflict of interest statement}

None of the authors have any conflict of interest to declare in this study.

\section{Acknowledgements}

The authors are grateful to Hans Arinell, statistician at Department of Neuroscience, Psychiatry, Uppsala University for statistical support, and to Meeri Sandelin, biomedical scientist in sleep, at University Hospital in Örebro, Department of Neurology, Sleepunit, for assisting us with scoring the actigraph recordings. 


\section{References}

1. Mallon L, Broman JE, Akerstedt T and Hetta J. Insomnia in Sweden: a population-based survey. Sleep Disord., 2014;2014:843126. doi: 10.1155/2014/843126.

2. Jansson-Fröjmark, $M$ and Lindblom, K. A bidirectional relationship between anxiety and depression, and insomnia? A prospective study in general population. J. Psychosom. Res., 2008, 64: 443-449. doi: 10.1016/j.jpsychores.2007.10.016

3. Vgontzas, AN, Liao, D, Pejovic, S, Calhoun, S, Karataraki, M and Bixler, EO. Insomnia with objective short sleep duration is associated with type 2 diabetes: A population-based study. Diabetes Care, 2009, 32: 1980-1985. doi: 10.2337/dc09-0284

4. Cappuccio, FP, D'Elia, L, Strazzullo, P and Miller, MA. Quantity and quality of sleep and incidence of type 2 diabetes: a systematic review and meta-analysis. Diabetes Care, 2010, 33: 414-420. doi: $10.2337 / \mathrm{dc} 09-1124$

5. Laugsand, LE, Strand, LB, Platou, C, Vatten, LJ and Janszky, I. Insomnia and the risk of incident heart failure: a population study. Eur. Heart J., 2014, 35: 1382-1393. doi:

10.1093/eurheartj/eht019

6. American Psychiatric Association: Diagnostic and statistical manual of mental disorders, fifth edition. Arlington, VA, American Psychiatric Association, 2013.

7. Vitiello MV, Larsen LH and Moe KE. Age-related sleep change: Gender and estrogen effects on the subjective-objective sleep quality relationships of healthy, noncomplaining older men and women. J Psychosom Res., 2004, 56: 503-510. doi: 10.1016/S00223999(04)00023-6

8. McCrae CS, Rowe MA, Tierney CG, Dautovich ND, Definis AL, and McNamara JP. Sleep complaints, subjective and objective sleep patterns, health, psychological adjustment, and daytime functioning in community-dwelling older adults. J Gerontol B Psychol Sci Soc Sci., 2005, 60: 182-189. doi: 10.1093/geronb/60.4.P182

9. Åkerstedt T, Schwarz J, Gruber G, Lindberg E, and Theorell-Haglöw J. The relation between polysomnography and subjective sleep and its dependence on age - poor sleep may become good sleep. J Sleep Res. 2016, 25: 565-570. doi: 10.1111/jsr.12407

10. Kyle SD, Morgan K, and Espie CA. Insomnia and health-related quality of life.

Sleep Med Rev., 2010, 14: 69-82. doi: 10.1016/j.smrv.2009.07.004 
11. Luyster FS, Choi J, Yeh CH, Imes CC, Johansson AE, and Chasens ER. Screening and evaluation tools for sleep disorders in older adults. Appl Nurs Res., 2015, 28: 334-340. doi: 10.1016/j.apnr.2014.12.007

12. Kushida CA, Littner MR, Morgenthaler T, Alessi CA, Bailey D, Coleman J Jr, Friedman L, Hirshkowitz M, Kapen S, Kramer M, Lee-Chiong T, Loube DL, Owens J, Pancer JP, and Wise M. Practice parameters for the indications for polysomnography and related procedures: an update for 2005. Sleep., 2005, 28: 499-521.

13. Ancoli-Israel S, Cole R, Alessi C, Chambers M, Moorcroft W, and Pollak CP. The role of actigraphy in the study of sleep and circadian rhythms. Sleep., 2003, 26: 342-392.

14. Vallières A, Morin CM. Actigraphy in the assessment of insomnia. Sleep., 2003, 26: $902-$ 906.

15. Paquet J, Kawinska A, and Carrier J. Wake detection capacity of actigraphy during sleep. Sleep., 2007, 30: 1362-1369.

16. Sivertsen B, Omvik S, Havik OE, Pallesen S, Bjorvatn B, Nielsen GH, Straume S, and Nordhus IH. A comparison of actigraphy and polysomnography in older adults treated for chronic primary insomnia. Sleep., 2006, 29: 1353-1358.

17. Rowe M, McCrae C, Campbell J, Horne C, Tiegs T, Lehman B, and Cheng J. Actigraphy in older adults: comparison of means and variability of three different aggregates of measurement. Behav Sleep Med., 2008, 6: 127-145. doi: 10.1080/15402000801952872

18. Harvey AG, Stinson K, Whitaker KL, Moskovitz D, and Virk H. The subjective meaning of sleep quality: a comparison of individuals with and without insomnia. Sleep., 2008, 31: 383-393.

19. Coates TJ, Killen JD, George J, Marchini E, Silverman S, and Thoresen C. Estimating sleep parameters: a multitrait--multimethod analysis. J. Consult. Clin. Psychol., 1982, 50: 345-352.

20. Sivertsen B, Omvik S, Pallesen S, Bjorvatn B, Havik OE, Kvale G, Nielsen GH, and Nordhus IH. Cognitive behavioral therapy vs zopiclone for treatment of chronic primary insomnia in older adults: a randomized controlled trial. JAMA., 2006, 295: 2851-2858. doi: $10.1001 /$ jama.295.24.2851 
21. Edinger JD, Olsen MK, Stechuchak KM, Means MK, Lineberger MD, Kirby A, and Carney CE. Cognitive behavioral therapy for patients with primary insomnia or insomnia associated predominantly with mixed psychiatric disorders: a randomized clinical trial. Sleep., 2009, 32: 499-510.

22. King HC, Spence DL, Hickey AH, Sargent P, Elesh R, and Connelly CD. Auricular acupuncture for sleep disturbance in veterans with post-traumatic stress disorder: a feasibility study. Mil Med., 2015, 180: 582-590. doi: 10.7205/MILMED-D-14-00451

23. Ma Y, Dong M, Mita C, Sun S, Peng CK and Yang AC. Publication analysis on insomnia:how much has been done in the past two decades? Sleep Med., 2015, 16: 820-826. doi: 10.1016/j.sleep.2014.12.028

24. Morin CM and Benca R. Chronic insomnia. Lancet., 2012, 379: 1129-1141. doi: $10.1016 / \mathrm{S} 0140-6736(11) 60750-2$

25. Cunnington D, Junge MF and Fernando AT. Insomnia: prevalence, consequences and effective treatment. Med. J. Aust., 2013, 199: 36-40. doi:10.5694/mja13.10718

26. Kalavapalli R and Singareddy R. Role of acupuncture in the treatment of insomnia: a comprehensive review. Complement. Ther. Clin. Pract., 2007, 13: 184-193

27. Salomonsen, LJ, Skovgaard, L, la Cour, S, Nyborg, L, Launsø, L and Fønnebø, V. Use of complementary and alternative medicine at Norwegian and Danish hospitals. BMC

Complement. Altern. Med., 2011, 11: 1-8. doi: 10.1186/1472-6882-11-4

28. Sjöling, M, Rolleri, M and Englund, E. Auricular acupuncture versus sham acupuncture in the treatment of women who have insomnia. J. Altern. Complement. Med., 2008, 14: 3946. doi: 10.1089/acm.2007.0544

29. Cheuk, CKL, Yeung, WF and Chung, KF. Acupuncture for insomnia. Cochrane Database Syst. Rev., 2012, Issue 9. doi: 10.1002/14651858.CD005472.pub3

30. Guo, J, Wang, LP, Liu, CZ, Zang, J, Wang, GL, Yi, JH, and Cheng, JL. Efficacy of acupuncture for primary insomnia: a randomized controlled clinical trial. Evid. Based Complement. Alternat. Med., 2013, 163850. doi: 10.1155/2013/163850

31. Yeung WF, Chung KF, Zhang SP, Yap TG, and Law AC. Electroacupuncture for primary insomnia: a randomized controlled trial. Sleep., 2009, 32: 1039-1047. 
32. Prisco MK, Jecmen MC, Bloeser KJ., McCarron KK., Akhter JE, Duncan AD, Balish MS, Amdur RL, and Reinhard MJ. Group Auricular Acupuncture for PTSD-Related Insomnia in Veterans: A Randomized Trial. Med. Acupunct., 2013, 25: 407-422. doi:

10.1089/acu.2013.0989

33. Bergdahl L, Broman JE, Berman AH, Haglund K, von Knorring L, and Markström A. Auricular Acupuncture and Cognitive Behavioural Therapy for Insomnia: A Randomised Controlled Study. Sleep Disord., 2016;2016:7057282. doi: 10.1155/2016/7057282

34. Bastien, $\mathrm{CH}$, Vallières, $\mathrm{A}$ and Morin, $\mathrm{CM}$. Validation of the insomnia severity index as an outcome measure for insomnia research. Sleep Med., 2001, 2: 297-307. doi: 10.1016/S13899457(00)00065-4

35. Bergdahl, L, Berman, AH and Haglund, K. Patients' experience of auricular acupuncture during protracted withdrawal. J. Psychiatr. Ment. Health Nurs., 2014, 21: 163-169. doi: 10.1111/jpm.12028

36. Currie, SR, Wilson, KG, Pontefract, AJ and deLaplante, L. Cognitive-behavioral treatment of insomnia secondary to chronic pain. J. Consult. Clin. Psychol., 2000, 68: 407416. doi: 10.1037/0022-006X.68.3.407

37. Ware J Jr, Kosinski M, and Keller SD. A 12-Item Short-Form Health Survey: construction of scales and preliminary tests of reliability and validity. Med. Care., 1996, 34: 220-233.

38. Kölling S, Steinacker JM, Endler S, Ferrauti A, Meyer T, and Kellmann M. The longer the better: Sleep-wake patterns during preparation of the World Rowing Junior Championships. Chronobiol. Int. 2016, 33: 73-84. doi: 10.3109/07420528.2015.1118384 39. Friedman L, Benson K, Noda A, Zarcone V, Wicks DA, O'Connell K, Brooks JO 3rd, Bliwise DL, and Yesavage JA. An actigraphic comparison of sleep restriction and sleep hygiene treatments for insomnia in older adults. J. Geriatr. Psychiatry Neurol., 2000, 13: 1727.

40. Espie CA, Fleming L, Cassidy J, Samuel L, Taylor LM, White CA, Douglas NJ, Engleman HM, Kelly HL, and Paul J. Randomized controlled clinical effectiveness trial of cognitive behavior therapy compared with treatment as usual for persistent insomnia in patients with cancer. J. Clin. Oncol., 2008, 26: 4651-4658. doi: 10.1200/JCO.2007.13.9006 
41. Carey TJ, Moul DE, Pilkonis P, Germain A, and Buysse DJ. Focusing on the experience of insomnia. Behav. Sleep Med., 2005, 3: 73-86. doi: 10.1207/s15402010bsm0302_2

42. Espie CA, MacMahon KM, Kelly HL, Broomfield NM, Douglas NJ, Engleman HM, McKinstry B, Morin CM, Walker A, and Wilson P. Randomized clinical effectiveness trial of nurse-administered small-group cognitive behavior therapy for persistent insomnia in general practice. Sleep., 2007, 30: 574-84. 